DOI 10.37882/2223-2982.2021.02-2.12

\title{
ДВЕ ТРАДИЦИИ ИЗУЧЕНИЯ МОДАЛЬНОСТИ. ПЛАН СОДЕРЖАНИЯ
}

\section{TWO TRADITIONS OF THE STUDY OF MODALITY. A CONTENT PLANE}

\section{Ezhkova}

Summary: The article traces the development of views on modality in the works of scholars from Russia and other countries from the point of view of the content plane. Domestic and foreign linguistic traditions of modality research are compared and analyzed. In conclusion, there is an attempt to identify the core of modality and give its own definition of this category. It is concluded that modality includes two main types of meanings - semantic and pragmatic modality. A proposal to distinguish modality and subjectivity as different categories of modus is put forward.

Keywords: modality, modus, modal meanings, subjective modality, subjectivity, deontic modality, epistemic modality.

\section{Введение}

K атегория модальности уже не одно десятилетие привлекает внимание специалистов из разных гуманитарных областей, которые занимаются проблемой соотношения высказывания и действительности. Эта категория, по мнению разных исследователей, включает в себя большое количество значений и средств их выражения, и проблема изучения модальности связана с приведением всех этих составляющих в систему. Чтобы решить эту проблему, необходимо найти корни данного понятия в науке, определить основные виды модальности в отечественном и зарубежном языкознании и на основании полученных данных установить терминологические соответствия в отношении данной категории.

В статье мы обзорно осветим ключевые исследования по модальности отечественных и зарубежных авторов, опубликованные с 50-ых гг. XX в. по сегодняшний день. В рамках отечественной лингвистической традиции модальность исследовали В.В. Виноградов, Н.Ю. Шведова, А.В. Бондарко, Г.А. Золотова, В.А. Плунгян, Е.В. Падучева, И.М. Кобозева, Т.В. Шмелева и многие другие специалисты в области семантики, синтаксиса, общего и типологического языкознания. Зарубежная традиция будет проиллюстрирована работами Ш. Балли, Ф. Палмера, Дж. Байби, И. Нютса, Х. Наррога и других ученых.

Обозначив основные различия в подходах отечественных и зарубежных авторов, мы выделим общие черты в понимании модальности, на основании кото-

\author{
Ежкова Виктория Андреевна \\ Аспирант, МГУ имени М.В. Ломоносова (Москва) \\ arien_anor@mail.ru
}

Аннотация: В статье прослеживается развитие взглядов на модальность в трудах ученых из России и других стран с точки зрения плана содержания. Отечественная и зарубежная лингвистические традиции исследования модальности сопоставляются и анализируются. В заключении предпринимается попытка выделить ядро модальности и дать собственное определение данной категории. Делается вывод о том, что модальность включает в себя два основных типа значений - семантическую и прагматическую модальность. Выдвигается предложение о разграничении модальности и субъективности как разных категорий модуса.

Ключевые слова: модальность, модус, значения модальности, субъективная модальность, субъективность, деонтическая модальность, эпистемическая модальность.

рых сформулируем собственное определение данной категории и определим ее место в системе модусных смыслов.

\section{Отечественная традиция изучения модальности}

Академик В.В. Виноградов одним из первых в отечественном языкознании дал определение модальности категории, указывающей на отношение к действительности с помощью различных лексико-грамматических средств [3, с. 55, 57]. В его исследовании еще не проведено терминологического разделения между объективной и субъективной модальностью, однако уже обозначен целый ряд средств (интонация, частицы, эмоциональнооценочная лексика и др.), которые служат выражению экспрессивно-модальных оттенков высказывания [3, с. 58-87]. Впоследствии эти оттенки были отнесены к субъективной модальности [11, с. 91].

Дальнейшее исследование категории основано на следующих подходах:

- Выделение объективной и субъективной модальности и дополнительных по отношению к ним значений («Русская грамматика», Г.А. Золотова, Е.В. Падучева, И.М. Кобозева).

- Использование вместо объективной и субъективной модальности других терминов со схожим семантическим наполнением (В.А. Плунгян, «Теория функциональной грамматики»).

- Определение модальности как способа выражения реальности/ирреальности (Т.В. Шмелева). 
Резюмируем точки зрения отечественных исследователей в таблице.

Таблица 1.

Модальность в трудах советских и российских ученых

\begin{tabular}{|c|c|}
\hline Работа & Основные идеи \\
\hline Виноградов 1950 & $\begin{array}{l}\text { Модальность как составляющая предикативности } \\
\text { представлена в каждом предложении. } \\
\text { Модальность также включает в себя различные } \\
\text { средства, которые выражают возможность, не- } \\
\text { обходимость, желание, волеизъявление, мораль- } \\
\text { но-этическую и эмоциональную оценки, стиль речи } \\
\text { и т.д. [3, с. 58-87] }\end{array}$ \\
\hline Шведова 1980 & $\begin{array}{l}\text { Два вида модальности - объективная и субъектив- } \\
\text { ная и примыкающие к ним две группы значений: } \\
\text { 1. значения возможности, желания, должен- } \\
\text { ствования, необходимости или вынужденности, } \\
\text { предстояния, готовности; 2. значения утверждения, } \\
\text { отрицания и вопроса [11, т.2, с. 214-216]. }\end{array}$ \\
\hline Золотова 1973 & $\begin{array}{l}\text { Три вида модальности - объективная, субъектив- } \\
\text { ная и внутрисинтаксическая [5, с. 140-157]. }\end{array}$ \\
\hline Падучева 2019 & $\begin{array}{l}\text { Три вида модальности - объективная, иллоку- } \\
\text { тивная и субъективная (установочная) и примы- } \\
\text { кающие к субъективной модальности значения } \\
\text { возможности и необходимости (оба значения } \\
\text { включают в себя три типа: онтологический, эписте- } \\
\text { мический, деонтический) [9, с. 86, 134-141]. }\end{array}$ \\
\hline Кобозева 2000 & $\begin{array}{l}\text { Два вида модальности - объективная и субъек- } \\
\text { тивная. Модальность включает в себя понятия } \\
\text { возможности, невозможности, необходимости. } \\
\text { Возможность бывает объективной и субъективной, } \\
\text { а невозможность и необходимость только объ- } \\
\text { ективной [7, с. 240-243]. }\end{array}$ \\
\hline Шмелева 1984 & $\begin{array}{l}\text { Модальность - квалификационная категория } \\
\text { модуса, относящая события к реальности или к } \\
\text { ирреальности }[13, \text { с. } 80-88] .\end{array}$ \\
\hline Бондарко 1990 & $\begin{array}{l}\text { Шесть видов модальностей, которые распреде- } \\
\text { ляются по типам оценок, выражаемых говоря- } \\
\text { щим (реальность-ирреальность; возможность, } \\
\text { необходимость или желательность; достоверность } \\
\text { сообщения; эмоциональная и качественная оценка; } \\
\text { утверждение или отрицание; коммуникативная } \\
\text { установка говорящего) [12, с. 59]. }\end{array}$ \\
\hline Плунгян 2003 & $\begin{array}{l}\text { Два вида модальности - ирреальная (включает } \\
\text { в себя значения возможности, необходимости; } \\
\text { желания) и оценочная [10, с. 308-317]. }\end{array}$ \\
\hline
\end{tabular}

\section{Зарубежная традиция изучения мохальности}

Одним из первых исследователей, который дал определение модальности в лингвистике, был Ш. Балли. Следуя логической линии понимания модальности, Ш. Балли предложил считать, что эксплицитное предложение как форма мысли состоит из двух компонентов. Первый компонент - это диктум, образующий представление говорящего о действительности, второй компонент - мо- дус, содержащий в себе модальность, благодаря которой говорящий производит психическую операцию над данным представлением [1, с. 43-48].

Большое значение для развития зарубежной традиции понимания модальности имели также взгляды Ф. Палмера. Его концепция модальности неоднократно переосмыслялась, например, в работе современного лингвиста Х. Наррога или классика типологии Дж. Байби. Отразим взгляды зарубежных исследователей в таблице.

Таблица 2.

Модальность в трудах зарубежных ученых

\begin{tabular}{|c|c|}
\hline Работа & Основные идеи \\
\hline Балли 1955 & $\begin{array}{l}\text { Предложение состоит из диктума (представление o } \\
\text { действительности) и модуса (психическая операция } \\
\text { говорящего над этим представлением). Модус со- } \\
\text { держит в себе модальность, которая включает мо- } \\
\text { дальный глагол и модальный субъект [1, с. 43-48]. }\end{array}$ \\
\hline Palmer 2001 & $\begin{array}{l}\text { Два вида модальности: } \\
\text { 1) пропозициональная (отношение говорящего к } \\
\text { истинно-ценностному или фактическому статусу } \\
\text { высказывания): } \\
\text { • эпистемическая; } \\
\text { • эвиденциальная. } \\
\text { 2) событийная (указание на потенциальность со- } \\
\text { бытий): } \\
\text { • деонтическая; } \\
\text { •динамическая [16, с. 3-8]. }\end{array}$ \\
\hline Лайонз 2003 & $\begin{array}{l}\text { Два вида модальности: } \\
\text { 1) объективная: } \\
\text { • эпистемическая; } \\
\text { • деонтическая. } \\
\text { 2) субъективная: } \\
\text { • эпистемическая; } \\
\text { • деонтическая [8, с. 346]. }\end{array}$ \\
\hline Бенвенист 1974 & $\begin{array}{l}\text { Три типа предложений в зависимости от модаль- } \\
\text { ности: утвердительные, вопросительные, повели- } \\
\text { тельные }[2, \text { c. } 140] \text {. }\end{array}$ \\
\hline Nuyts 2019 & $\begin{array}{l}\text { Четыре вида модальности: } \\
\text { 1) динамическая (описание способности/возмож- } \\
\text { ности, а также нужды/необходимости/потребно- } \\
\text { сти агенса осуществить положение вещей, выра- } \\
\text { женное в предложении); } \\
\text { 2) деонтическая (описание степени моральной } \\
\text { приемлемости выраженного в высказывании со- } \\
\text { стояния дел); } \\
\text { 3) эпистемическая (оценка говорящим вероятно- } \\
\text { сти того, что положение дел, выраженное в пред- } \\
\text { ложении, имеет место в действительности); } \\
\text { 4) буломаическая (указание на степень симпатии } \\
\text { или антипатии говорящего к состоянию дел, выра- } \\
\text { женному в предложении) [15, с. 33-40]. }\end{array}$ \\
\hline
\end{tabular}




\begin{tabular}{|c|c|}
\hline Работа & Основные идеи \\
\hline $\begin{array}{l}\text { Bybee, Perkins, } \\
\text { Pagliuca } 1994\end{array}$ & $\begin{array}{l}\text { Четыре вида модальности: } \\
\text { 1) ориентированная на агенса (указание на усло- } \\
\text { вия выполнения агенсом действий, выраженных в } \\
\text { главном предложении); } \\
\text { 2) ориентированная на говорящего (речевые акты, } \\
\text { направленные на адресата и вынуждающие его } \\
\text { прозвести некоторое действие); } \\
\text { 3) эпистемическая (оценка степени истинности } \\
\text { предложения); } \\
\text { 4) подчинительная (модальность в придаточных } \\
\text { предложениях - изъяснительном, цели и уступки) } \\
\text { [17,с. 177-181]. }\end{array}$ \\
\hline Narrog 2012 & $\begin{array}{l}\text { Девять видов модальности, которые указывают на } \\
\text { фактический статус пропозиции (возможность или } \\
\text { необходимость) в разных отношениях [14, с. 6-10]. }\end{array}$ \\
\hline
\end{tabular}

\section{Зак^ючение}

Проанализировав взгляды отечественных и зарубежных ученых на модальность, мы можем сделать следующие выводы:

- В отечественной лингвистической традиции доминируют представление о модальности как о категории, имеющей как минимум два основных значения - объективная и субъективная модальность. В зарубежном языкознании чаще выделяются типы модальности, пришедшие из логики, например, деонтическая и эпистемическая модальность. В целом логическая трактовка модальных значений чаще всего встречается в трудах именно зарубежных специалистов. В отечественном языкознании, особенно в работах В.В. Виноградова, модальность с самого начала изучалась как сугубо лингвистическая категория в связи с ее особыми проявлениями в разговорной или письменной художественной речи, хотя для исследований по семантике характерно обращение в том числе к логике.

- Различия в терминологии, языке как предмете исследования и собственно в лингвистической традиции являются источником разнообразия взглядов на модальность в трудах ученых из разных стран.

На основании полученных выводов считаем целесообразным попытаться дать собственное определение модальности. С точки зрения семантики модальность относится к неассертивным смыслам предложения, которые составляют отдельный аспект его пропозиционального компонента. Дополняя это положение, можем отметить, что модальность представляет собой дополнительные по отношению к основному, диктумному содержанию смыслы, которые либо указывают на фактический статус предложения (то же, что статус ситуации по отношению к реальному миру у Е.В. Падучевой [9, с. 85]), если речь идет о пропозициональном компоненте, либо служат выполнению иллокутивной функции высказывания, если речь идет о прагматическом компоненте ${ }^{1}$.

Поясним, что имеется в виду под фактическим статусом предложения. Как было отмечено, модальность относится к неассертивным смыслам. Это также заметил Палмер: он писал, что модальность указывает не на недействительность, а на то, что не утверждается [16, с. 4]. Дополняя позицию Палмера, отметим, что предложения, в которых не утверждается некоторое состояние дел как действительное или недействительное, то есть предложения, которые передают значения возможности или необходимости, являются модальными. Так, пример (1) не является утверждением за счет присутствия маркеров возможности, а пример (2) является утверждением и не содержит в себе модального компонента.

1. «Возможно, после вынесения Государственной Думой вотума недоверия правительству ничего не произойдет, а может, это вызовет острейший правительственный кризис, чреватый самыми непредсказуемыми последствиями» [6, с.167].

2. После вынесения Государственной Думой вотума недоверия правительству ничего не произойдет или это вызовет острейший правительственный кризис, чреватый самыми непредсказуемыми последствиями.

При этом если что-то не утверждается, это не значит, что оно отрицается. Отрицание - это операция над утверждением, которая преобразует его в противоположное утверждение. Например: Мальчик бежит => Мальчик не бежит. Модальность появляется там, где что-то не утверждается в своей положительной или отрицательной форме, например, Возможно, мальчик бежит или Возможно, мальчик не бежит или Если бы мальчик побежал или Мальчик, беги! Таким образом, в нашем понимании утверждение противопоставлено не отрицанию. Утверждение, связывая предложение с планом действительности, противопоставлено неутверждаемым предложениям, соотносимым с ирреальными планами возможности и необходимости. Аналогичный ход рассуждения обнаруживаем у других исследователей [5, с. 146-147].

Теперь поясним, что имеется в виду под модальностью, которая с точки зрения прагматики служит выполнению иллокутивной функции высказывания. Объектом

Понятие о плане содержания предложения, который включает в себя пропозициональный, «упаковочный» и прагматический компоненты встречаем у И.М. Кобозевой [7, с. 217-265]. 
Таблица 3.

Соотношение значений семантической и прагматической модальности

\begin{tabular}{|l|l|l|l|}
\hline $\begin{array}{c}\text { Семантическая } \\
\text { модальность }\end{array}$ & \multicolumn{1}{|c|}{ Пример } & \multicolumn{1}{|c|}{$\begin{array}{c}\text { Прагматическая } \\
\text { модальность }\end{array}$} & \multicolumn{1}{c|}{ Пример } \\
\hline действительно & Tатьяна пишет письмо. & утверждение & Tатьяна пишет письмо. \\
\hline возможно & $\begin{array}{l}\text { Возможно, Tатьяна пишет } \\
\text { письмо. }\end{array}$ & просьба, вопрос-просьба и др. & $\begin{array}{l}\text { Tатьяна, может быть, } \\
\text { напишешь письмо? }\end{array}$ \\
\hline невозможно & $\begin{array}{l}\text { Невозможно, чтобы Tатья- } \\
\text { написала письмо. }\end{array}$ & запрет & Tатьяна, не пиши письмо. \\
\hline необходимо & $\begin{array}{l}\text { Необходимо, чтобы Tатья- } \\
\text { на написала письмо. }\end{array}$ & $\begin{array}{l}\text { команда, приказ, настоятель- } \\
\text { ная просьба и др. }\end{array}$ & $\begin{array}{l}\text { Татьяна, ты должна } \\
\text { написать письмо. }\end{array}$ \\
\hline
\end{tabular}

исследования при таком подходе к модальности является не предложение, а высказывание, т.е. единица речи, рассматриваемая в соотнесенности с ситуацией общения, а значит, и с прагматикой. В речи некоторые высказывания могут становиться речевыми актами, обладающими иллокутивной силой, иными словами, выражающими коммуникативное намерение говорящего. Модальность как лингвистическая категория помогает передать это коммуникативное намерение, превращая речевые акты в вопросы, просьбы, запреты, команды и т. д.

При этом не все иллокутивные речевые акты будут модальными, а только те, которые коррелируют с ирреальными планами возможности и необходимости. Взяв за основу концепцию связи модальных смыслов логика Г.Х. фон Вригта [4, с. 246], представим корреляцию значений семантической и прагматической модальности.

Таким образом, мы выделяем два типа модальности:
1. семантическая модальность, которая устанавливает отношение между предложением и действительностью;

2. прагматическая модальность, которая устанавливает отношение между высказыванием и участниками коммуникации.

При этом различные смыслы, которые традиционно относятся к субъективной модальности, на наш взгляд, должны быть вынесены за скобки модальности и включены в другую модусную категорию, которую можно было бы назвать субъективность или субъективная квалификация предложения (термин В.В. Виноградова).

В соответствии с этой позицией модусная категория модальности является способом выражения ирреальности событий с точки зрения семантики и прагматики, а модусная категория субъективности служит выражению отношения субъекта к сказанному с помощью предикатов пропозициональной установки и других средств.

\section{ЛИТЕРАТУРА}

1. Балли Ш. Общая лингвистика и вопросы французского языка. М.: Издательство иностранной литературы, 1955.416 с.

2. Бенвенист Э. Общая лингвистика. М.: Прогресс, 1974. 448 с.

3. Виноградов В.В. 0 категории модальности и модальных словах в русском языке // Труды Института русского языка. М-Л, 1950. Т. 2. С. 53-87.

4. Вригт Г.Х. фон. Логико-философские исследования: Избр. тр. М.: Прогресс, 1986.600 с.

5. Золотова Г.А. Очерк функционального синтаксиса русского языка. М.: Издательство «Наука», 1973. 351 с.

6. Избранные выступления депутатов Государственной Думы с 1906 года до наших дней / Под общей ред. С.Е. Нарышкина. М: Издание Государственной Думы, 2013. 304 с.

7. К Кобозева И.М. Лингвистическая семантика: Учебное пособие. М.: Эдиториал УРСС, 2000. 352 с.

8. Лайонз Дж. Лингвистическая семантика: Введение. М.: Языки славянской культуры, 2003. 397 с.

9. Падучева Е.В. Эгоцентрические единицы языка. М.: Издательский Дом ЯСК, 2019. 440 с.

10. Плунгян В.А. Общая морфология: Введение в проблематику: Учебное пособие. М.: Едиториал УРСС, 2003. 384 с.

11. Русская грамматика. Том ІІ. Синтаксис / Под ред. Н.Ю. Шведовой. М.: Издательство «Наука», 1980. 712 с.

12. Теория функциональной грамматики. Темпоральность. Модальность / Под ред. А.В. Бондарко. Л.: Издательство «Наука», 1990. 264 с.

13. Шмелева Т. В. Смысловая организация предложения и проблема модальности // Актуальные проблемы русского синтаксиса / Под ред. К.В. Горшковой, Е.В. Клобукова. М., 1984. С. 78-100.

14. Narrog H. Modality, Subjectivity, and Semantic Change. A Cross-Linguistic Perspective. Oxford: Oxford University Press, 2012. 352 p.

15. Nuyts J. Analyses of the Modal Meanings // The Oxford Handbook of Modality and Mood. Oxford: Oxford University Press, 2019. pp. 31-49.

16. Palmer F.M. Mood and Modality. Cambridge: Cambridge University Press, 2001. 236 p.

17. The evolution of grammar: tense, aspect, and modality in the languages of the world/Joan Bybee, Revere Perkins, and William Pagliuca. Chicago and London: The University of Chicago Press, 1994. 415 p. 